\title{
O IMPERATIVO DA FELICIDADE COMO BEM SUPREMO PARA BYUNG-CHUL HAN: ONDE ENTRETENIMENTO E PAIXÃO SE TOCAM?
}

\author{
The imperative of happiness as a well supreme for \\ Byung-Chul Han: where entertainment and passion touch \\ El imperativo de la felicidad como bien supremo para \\ Byung-Chul Han: donde el entretenimiento y la pasión \\ se tocan
}

\author{
Leonardo Pachelle \\ Universidade de São Paulo, São Paulo, Brasil. \\ Pós-graduando em Cultura Material e Consumo: perspectivas Semiopsicanalíticas pela Escola de Comuni- \\ cações e Artes da Universidade de São Paulo (ECA-USP). Possui graduação em Jornalismo pela Universi- \\ dade Presbiteriana Mackenzie e pós-graduação em Gestão Estratégica em Comunicação Organizacional e \\ Relações Públicas pela Escola de Comunicações e Artes da Universidade de São Paulo (ECA-USP). \\ E-mail: leo.jornal@hotmail.com
}

RESUMO Bom Entretenimento: uma desconstrução da história da paixão ocidental apresenta a convergência oculta existente entre paixão e entretenimento, demonstrando como ambos estão historicamente conectados. Nesse sentido e, por meio do diálogo com filósofos que abordam o tema do bom e do belo no contexto da arte, Byung-Chul Han propõe uma metateoria do entretenimento para explicar sua ascensão na sociedade ocidental. Dentro dessa observação, é examinado como paixão e entretenimento se alternam enquanto representações do real e do fictício e suas respectivas semelhanças.

PALAVRAS-CHAVE Arte, Entretenimento, Ficção, Paixão, Real.

\begin{abstract}
Good Entertainment: a deconstruction of the western passion narrative presents the hidden convergence between passion and entertainment, demonstrating how both elements are historically linked. Thus, the thought of philosophers who approach the theme of the good and the beauty in the context of art was adopted by Byung-Chul Han to propose a metatheory of entertainment to explain its rise in Western society. According to this observation, the way passion and entertainment alternate as representations of the real and the fictional and their respective similarities is studied.
\end{abstract}

KEYWORDS Art, Entertainment, Fiction, Passion, Real.

RESUMEN Buen entretenimiento: una deconstrucción de la historia occidental de la pasión presenta la convergencia oculta entre la pasión y el entretenimiento, demostrando cómo están históricamente conectados. En este sentido, a partir del diálogo con filósofos que abordan el tema del bien y lo bello en el contexto del arte, Byung-Chul Han propone una metateoría del entretenimiento para explicar su auge en la sociedad occidental. En esta observación, se examina cómo la pasión y el entretenimiento se alternan como representaciones de lo real y lo ficticio y sus respectivas similitudes.

PALABRAS CLAVE Arte, Entretenimiento, Ficción, Pasión, Real. 
Nas suas obras anteriores, Byung-Chul Han indicou a supressão de fronteiras provocada pela expansão da globalização rumo ao capital como marco simbólico da quebra do paradigma pautado na negatividade do desconhecido e do inimigo. Segundo o autor, essa mudança apontaria para a chegada de um novo modelo que privilegia no excesso de positividade o desempenho desenfreado do ser. Em outras palavras, a sociedade ocidental estaria se tornando uma sociedade do cansaço. Nesse sentido, a sociedade do cansaço seria a sociedade da potencialização do doping em vista da performance, "aquela que por excesso da elevação do desempenho leva a um infarto da alma” (HAN, 2017, p. 71). Ou mesmo, uma sociedade que possibilitaria por meio do doping o alcance de um desempenho sem desempenho (HAN, 2017, p. 69).

Não obstante, se entendermos a história da sociedade ocidental também como a história da paixão, o desempenho transvestido de doping seria uma nova fórmula de paixão e, portanto, um vetor de corrupção do jogo, pois, quando submetido à produção, o entretenimento não passaria de jogo gamificado. Segundo Byung-Chul Han, dessa associação entre entretenimento gamificado e paixão surgiria o "infarto da alma”, entretenimento caricatural que se degradaria em desligamento espiritual. Para haver uma mudança nessa condição, o autor analisa como a superação da paixão hedonista pode retomar não somente o bom entretenimento, mas também o belo entretenimento, por meio do diálogo com o pensamento de Hegel, Niezstche, Adorno e Kant, e a partir de uma dialética que desconstrói a história ocidental do entretenimento, considerando a análise de supostos paradoxos existentes entre paixão e entretenimento em momentos históricos distintos.

No primeiro capítulo, o autor observa como A paixão segundo São Mateus, oratório de Johann Sebastian Bach, causou alvoroço na época que foi tocada na igreja, (1727) despertando sentimentos ambíguos com relação à estrutura musical apresentada na obra - entrevendo um debate com relação ao sacro e o profano. Nesse contexto, apreciador e amante constituiriam o novo público musical, sendo ambos adeptos da paixão, espécie de bálsamo embriagante que colocaria o cultivo do gosto musical acima da ordem divina, esvaziando, portanto, o significante de Deus e trazendo à tona uma nova leveza para a música - que Nietzsche interpreta como fórmula de liberdade. Assim, a música, ao fazer uso e promover esse deleite, demonstraria que não somente do divino é feito o prazer, mas, também, do ânimo, sendo ambos inseparáveis na sua doçura.

No capítulo posterior, é analisada a dicotomia entre arte séria versus arte que entretém (clássico x popular) a partir da música de Gioachino Rossini, compositor visto por Robert Schumann como "pintor decorativo, cujos arabescos e ornamentos melódicos serviriam apenas ao prazer sensível, à embriaguez desprovida de verdade e de espírito" (HAN, 2019, p. 41). Segundo Richard Wagner, a "marca do bom" na arte estaria em um "estar aí para si mesmo", que não carece de nenhum público para ser reconhecido. Esse contraponto é articulado por Byung-Chul Han com a afirmação de que "a música mais bela, que converge com a pura felicidade, ressoa talvez, justamente, no submundo" (HAN, 2019, p. 60). Ou seja, a música de entretenimento (U-musik), criticada por Adorno, seria, ao contrário, um não-impedimento e, também, uma capacidade de viver.

O terceiro capítulo discute a essência do luxo, apoiando-se nas ideias de Wagner, Kant e Adorno. Para este, o luxo seria a expressão da felicidade não-falsificada, sendo, desse modo, constitutivo para arte. Diante desse pensamento, Byung-Chul Han observa que a ausência de 
coação ou ausência de preocupação seria igualmente uma forma de luxo presente no entretenimento - que apontaria para o extremo no qual entretenimento e arte se tocariam.

Em seguida, o quarto capítulo aborda o conceito de Satori, que seria sob a visão oriental um objeto da afirmação e também do entretenimento que não teria a paixão pela verdade como alvo. O pressuposto do autor é demonstrar que a paixão ou a ênfase da verdade não seriam necessariamente uma pressuposição necessária para o refinamento de formas de expressão estéticas. Em outras palavras, para o entretenimento.

No capítulo quinto, Byung-Chul Han dialoga com o pensamento de Kant, La Mettrie e Luhmann para refutar a dicotomia entre sensibilidade versus razão proposta por Kant. Em contraponto a Kant, que devido ao seu sentido abstrato ignora a confiabilidade dos sentimentos (HAN, 2019), o autor reafirma a força do hábito pré-reflexivo diante da decisão consciente argumentando que o entretenimento, por ser advindo do mito e da narrativa, seria "mais efetivo do que o imperativo moral e mais obrigante do que a razão e a verdade” (HAN, 2019, p. 116).

Posteriormente, no capítulo sexto, são debatidos os conceitos de arte agradável (U-kunst) em oposição à arte bela (E-kunst) por meio do pensamento de Kant. Enquanto a arte agradável seria dominada pelo gozo, a arte bela se voltaria para o conhecimento. Novamente, ByungChul Han desconstrói esse suposto antagonismo, apontando que tanto o entretenimento e a razão são saudáveis e que essa saúde é um ponto de convergência no qual a razão e o entretenimento se encontrariam.

O ser como paixão é o tema do capítulo sétimo. Nele, o autor comenta o entendimento de Heidegger sobre as mídias como instância falsificadora do real. Para Byung-Chul Han essa premissa seria demasiadamente arbitrária, pois faltaria a essa concepção uma maior serenidade para com o mundo. Nesse sentido: "a sua linguagem da paixão é violenta no sentido de que ela trabalha de maneira muito seletiva e excludente. Ela não é afável" (HAN, 2019, p. 41, grifo do autor).

No oitavo capítulo, o autor analisa um conto de Kafka para examinar se a arte enquanto um agir passional frente à um fazer negativo despontaria em um prazer invertido. A essa proposição, Byung-Chul Han confronta o artista da fome com o animal hedonista que afirma a vida positivamente. Em uma situação onde ambos estariam trancados em uma cela, o autor afirma que a paixão destes não se distinguiria fundamentalmente, pois, tanto o artista da fome quanto o animal hedonista dividem entre si o imperativo da felicidade como bem-supremo, embora divirjam no modo de apreensão dessa felicidade (negatividade/positividade).

Na sequência, o autor aborda o pensamento de Rauschenberg, que reafirma a arte como uma distração do mundo explícita. Sob esse ponto de vista, Byung-Chul Han separa os conceitos de serenidade e paixão para demonstrar que nem o entretenimento, tão pouco a paixão, possuem a qualidade do afável em sua essência.

Por fim, no décimo e último capítulo, o autor faz uma metateoria do entretenimento para explicar a ascensão do entretenimento na sociedade ocidental, pautando-se no poder sedutor narrativo para com os seres humanos. Como síntese, o autor afirma que se a totalização do entretenimento na realidade pode aparecer como declínio para o espírito da paixão: "Em seu fundamento paixão e entretenimento são irmanados" (HAN, 2019, p. 206).

Em suma, em Bom Entretenimento, Byung-Chul Han contrapõe entretenimento e paixão enquanto instâncias não-antagônicas de modo 
a examinar o paradoxo existente no homo doloris [homem da dor], que carrega o sofrimento em busca da redenção e penhora sua felicidade em troca de uma bem-aventurança para capitalizar à intensificação da paixão em prazer desprovido de sentido. Diante desse paradoxo, o autor afirma haver um ponto de convergência entre entretenimento e paixão, uma vez que o entretenimento puro, desprovido de sentido, se aproximaria do sentido puro de paixão: "Ao sorriso do tolo se assemelha fantasmagoricamente o rosto distorcido de dor do homo doloris [homem da dor]" (HAN, 2019, p. 10, grifo do autor).

Sob esse ponto de vista, a história do ocidente é entendida também como uma história da paixão, sendo esta sustentada pela sucessão de construções e desconstruções de mitos e narrativas - elementos que também estariam presentes intrinsecamente na estrutura do entretenimento - e um método eficaz para manutenção da ordem moral e social: "Mais efetivo do que a coação e o dever é o método que se arreda em histórias e que se enreda em tensões” (HAN, 2019, p. 115-116, grifo do autor).

\section{REFERÊNCIAS}

HAN, B-C. Bom entretenimento: uma desconstrução da história da paixão ocidental. Tradução de Lucas Machado. Petrópolis: Vozes, 2019.

HAN, B-C. Sociedade do cansaço. Tradução de Enio Paulo Giachini. Petrópolis: Vozes, 2017. 